\title{
Assessment of Cardiac Autonomic Function by Using Heart Rate Turbulence in Behcet's Disease
}

\author{
Onder Akci'1, Mustafa Aldemir², Fatma Yaman³, Ozlem Solak³, Sadık Volkan Emren4, \\ Ersel Onrat ${ }^{1}$, Alaeddin Avsar ${ }^{1}$ \\ ${ }^{1}$ Cardiology Department, School of Medicine, Afyon Kocatepe University, Afyonkarahisar, Turkey \\ ${ }^{2}$ Cardiovascular Surgery Department, School of Medicine, Afyon Kocatepe University, Afyonkarahisar, Turkey \\ ${ }^{3}$ Physical Medicine and Rehabilitation Department, School of Medicine, Afyon Kocatepe University, \\ Afyonkarahisar, Turkey \\ ${ }^{4}$ Cardiology Department, Afyon State Hospital, Afyonkarahisar, Turkey \\ Email: draldemir@yahoo.com
}

Received 1 September 2014; revised 1 October 2014; accepted 29 October 2014

Copyright (C) 2014 by authors and Scientific Research Publishing Inc.

This work is licensed under the Creative Commons Attribution International License (CC BY).

http://creativecommons.org/licenses/by/4.0/

(c) (i) Open Access

\section{Abstract}

Behcet's disease (BD) is a chronic inflammatory disorder that can affect many systems in the body. Cardiac involvement increases the risk of cardiovascular mortality and occurs in $1 \%-5 \%$ of patients with BD. Ventricular arrythmias are believed to be the cause of this increased risk of cardiovascular mortality and it is also thought to be related with cardiac autonomic dysfunction. Heart rate turbulence (HRT) is a new predictor of cardiac autonomic activity. HRT is an independent and powerful predictor of mortality. In this study, we investigated the cardiac autonomic activity which can be determined by HRT in patients with BD. Forty patients with BD (20 men, mean age: $40 \pm 9$ years, range: 27 - 55 years) were diagnosed according to the International Study Group Criteria (ISGC) and gender and age matched healthy volunteers (20 men, mean age: $39 \pm 8$ years, range: 26 - 56 years) were included in this study. All of the participants (patients and controls) underwent 24 hours Holter electrocardiogram. HRT parameters, turbulence onset (T0) and turbulence slope (TS) were calculated with HRT (View Version 0.60-0.1 of Software Program). There were no significant differences in TO and TS values between patients with BD and control subject (TO-BD: $0.014 \pm 0.03$, TO-Control: $0.011 \pm 0.04$; TS-BD: $7.88 \pm 4.9$, TS-Control: $9.42 \pm 6.7$ respectively). Although increased cardiovascular mortality rates in BD have been shown in many studies, HRT values-detecting the risk of sudden death-do not seem to be altered in this disease.

\section{Keywords}

Behcet's Disease, Heart Rate Turbulence, Sudden Cardiac Death, Cardiac Autonomic Activity

How to cite this paper: Akci, O., Aldemir, M., Yaman, F., Solak, O., Emren, S.V., Onrat, E. and Avsar, A. (2014) Assessment of Cardiac Autonomic Function by Using Heart Rate Turbulence in Behcet's Disease. World Journal of Cardiovascular Surgery, 4, 193-199. http://dx.doi.org/10.4236/wjcs.2014.411028 


\section{Introduction}

Behcet's disease (BD) is a chronic disorder characterized by acute exacerbations affecting multi-organ system. It is an inflammatory disorder which can be classified as autoimmune or autoinflammatory disease. Although etiology has not been clarified yet, the most acceptable opinion includes genetic background (Human leukocyte antigen (HLA)-B 51, one of the numerous split antigens of HLA-B 5) and some microorganisms or their antigens such as; herpes simplex virus, streptococci, staphylococci, or Escherichia species [1]. The prevalence of BD has been reported as 5.2 per 100,000 population (95\% CI 0.64 - 9.84), and although some studies in the literature report higher incidence of BD among women, this issue is contradictory in some other studies [2]. Uveitis, dermal lesions, oral and genital ulsers usually can be encountered along the course of BD [3]. Cardiovascular involvement characterized with endocarditis, myocarditis, pericarditis, intracardiac thrombi, endomyocardial fibrosis, coronary arteritis, myocardial infarction and valve disease may occur rarely [4]-[8].

It is shown that patient with BD has an increased mortality rates compared with normal population. Some of the predictors of mortality associated with $\mathrm{BD}$ have been identified. Arterial involvement is one of the predictors inreasing mortality in patients with BD. It is well known that sudden death can be seen in this disease [9]-[13]. Ventricular arrythmias are the most common cause of sudden cardiac death in most of the diseases. Dysfunction of cardiac autonomic activity is one of the causes of ventricular arrythmias. Autonomic nervous system such as central nervous system may be involved in Behcet’s disease [14] [15].

Some of the noninvasive parameters for the prediction of cardiac autonomic function such as heart rate variability (HRV), baroreflex sensitivity (BRS) and heart rate turbulence (HRT) have been identified. All of these tests assess the autonomic and reflex modulations of cardiac functions. Deterioration of HRT is correlated with BRS impairment. HRT deterioration reflects cardiac autonomic dysfunction [16]. HRT expresses ventriculophasic sinus arrhythmia, i.e., the early acceleration and the late deceleration of sinus rhythm after single ventricular premature beat (VPB), and it is considered to reflect autonomic nervous system function. HRT is an independent and powerful predictor of mortality and sudden cardiac death in various cardiac abnormalities [17] [18]. In our knowledge, there has been no previous study about HRT parameters in patients with BD.

In this study, we aimed to evaluate cardiac autonomic function by measuring HRT method which could be responsible for the higher rates of cardiovascular deaths in patients with BD.

\section{Method}

\subsection{Study Population}

Fourty patients with Behcet's disease (20 men, age: $40 \pm 9$ years, range: 27 - 55 years) diagnosed according to the International Study Group Criteria-ISGC, and age and gender matched healty volunteers without known cardiovascular disease (20 men, age: $39 \pm 8$ years, range: 26 - 56 years) were included in this study. Mean duration time of the disease was $7.7 \pm 6.3$ years (range: 1 - 18 years). Only patients in remission defined according to the clinical and laboratory data were included in this study. Before the study, all participants of this study were informed of the trial and provided written informed consent.

patients with unstable angina, myocardial infarction, heart failure, hypertension, diabetes mellitus, valvular heart disease, non-sinus rhythm, hyperthyroidism, left ventricular hypertrophy, electrolyte disturbances, and other systemic disorders (e.g. chronic renal failure, hepatic failure), smokers, drug users (especially betablockers and/or antiarrhythmic drugs) were excluded form the study. Physical examinations and resting 12-lead electrocardiograms (ECGs) of the participants were normal. Routine biochemical and hematological values including fasting blood glucose, blood urea nitrogen, serum electrolytes, thyroid hormones, and hemoglobin levels were in normal ranges.

\subsection{4-Hour Holter Electrocardiogram and HRT}

All participants underwent 24-hour Holter ECG. Holter recordings were analyzed with Reynolds Medical Pathfinder Software Version V8.255 (Hereford, England). Turbulence onset (TO) and turbulence slope (TS) values were calculated with the HRT by View Version 0.60-0.1 Software Program (Munich, Germany). While determining the HRT, abnormal beats and areas of artifact, which were accepted as VPB by the computer, were manually identified and excluded. Measurements of HRT were calculated by the original method which has been performed previosly by Schmidt et al. [18] as shown in Figure 1. TO, which is a measure of the early sinus 

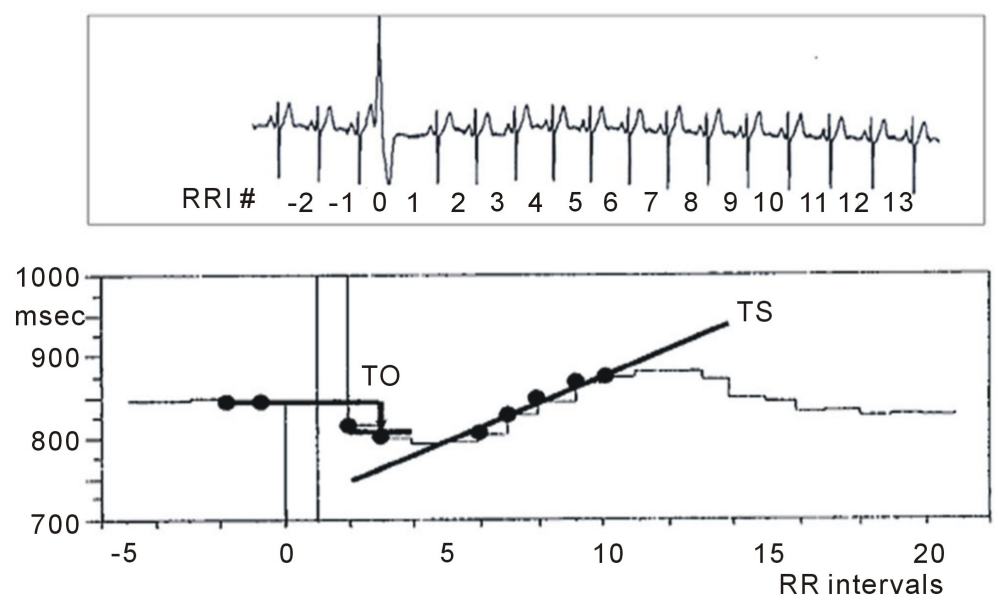

Figure 1. Calculation of heart rate turbulance.

acceleration after a VPB, is expressed as percentage and calculated by following formula:

$$
\mathrm{TO}=\frac{\left(\mathrm{RR}_{1}+\mathrm{RR}_{2}\right)-\left(\mathrm{RR}_{-2}+\mathrm{RR}_{-1}\right)}{\left(\mathrm{RR}_{-2}+\mathrm{RR}_{-1}\right)} \times 100
$$

where $R R_{1}$ and $R R_{2}$ are the first and second sinus $R R$ intervals after the VPB, and $R R_{-1}$ and $R R_{-2}$ are the first and second sinus RR intervals preceeding the VPB.

Turbulence slope (TS) is a measure of sinus deceleration rate following the sinus acceleration after a VPB. It is accepted as a maximal positive slope among all slopes of a series of regression lines obtained from all sequences of five consecutive RR intervals (within the first 20 sinus rhythm intervals after a VPB), and expressed as ms/RR. TO was calculated for all VPBs separately and obtained as an average value, whereas TS was calculated based on an average local tachogram.

\subsection{Statistical Analysis}

Statistical analyses were performed with SPSS for Windows version 11.0 (SPSS Inc, Chicago, IL, USA). Data are expressed as number (\%) or the mean \pm SEM (standard error of mean). Comparisons between independent groups were performed by using Student $t$ test. A p value $<0.05$ was considered as statistically significant.

\section{Results}

All patients completed the study. Demographic properties of the patients with behcet's disease and control groups are shown in Table 1. In all participants, rhythm was sinus and none of them had pacemaker. HRT parameters, TO and TS did not differ significantly between the two study groups, as shown in Table 2 (TO-BD: $0.014 \pm 0.03$ vs TO-Control: $0.011 \pm 0.04$; TS-BD: $7.88 \pm 4.96$ vs TS-Control: $9.42 \pm 6.7$ respectively).

\section{Discussion}

In this present study, the diagnosis of BD has been based on the diagnostic criteria by Japanese and/or International Study Group [19] Behcet's disease leads to some problems in many organ systems. Vascular involvement is seen in $3 \%-29 \%$ of patients with BD. Vasculitis are observed as venosus and/or arterial inflammations. The most encountered vascular lesion is superficial vein thrombosis [20]-[22]. Arterial involvement is less frequent than venous involvement. Carotid, pulmonary, aortic, iliac, femoral and popliteal arteries may also be involved. Less frequently, renal arteries may also be effected [23]. Although acute coronary syndrome due to coronary arterial involvement is a very rare complication, myocardial perfusion defect has been shown with myocardial perfusion scintigraphy in $56 \%$ of the patients with BD [24].

Cardiac involvement was 6\% in 807 patients with BD [21]. Cardiac lesions were the most frequent arterial involvement in $\mathrm{BD}$ and pericarditis was the most frequent cardiac lesion in their study. The other cardiac disorders related with BD were as follows: "endocarditis, intracardiac thrombi, myocardial infarction, endo- 
Table 1. Demographic properties of the patients with Behcet's disease and control group.

\begin{tabular}{cccc}
\hline & Behcet’s disease (n: 40) & Control group (n: 40) & p \\
\hline Age (years) & (Mean \pm SD) & (Mean \pm SD) & 0.654 \\
Height (cm) & $40.0 \pm 8.9$ & $39.9 \pm 8.4$ & 0.996 \\
Weight (kg) & $166.9 \pm 8.4$ & $169.4 \pm 8.3$ & 0.299 \\
BMI (kg/m²) & $73.8 \pm 13.8$ & $73.6 \pm 11.9$ & 0.847 \\
Heart rate (beats/min) & $26.3 \pm 4.0$ & $25.0 \pm 4.9$ & 0.813 \\
SBP (mmHg) & $75.4 \pm 3.6$ & $74.8 \pm 3.4$ & $0.956^{*}$ \\
DBP (mmHg) & $115.9 \pm 10.6$ & $115.7 \pm 9.8$ & $0.781^{*}$ \\
Sex (Male \%) & $72.2 \pm 5.7$ & $72.5 \pm 6.7$ & 1.000 \\
\hline
\end{tabular}

BMI: Body mass index; SBP: Systolic blood pressure; DBP: Diastolic blood pressure; ${ }^{*}$ Mann-Whitney U student-t test.

Table 2. Turbulance onsets and turbulance slopes of two groups.

\begin{tabular}{cccc}
\hline & Behcet's disease (n: 40) & Control group (n: 40) & \\
\hline & (Mean \pm SD) & (Mean \pm SD) & 0.141 \\
Turbulence onset & $0.014 \pm 0.03$ & $0.011 \pm 0.04$ & 0.247 \\
\hline Turbulence slope & $7.879 \pm 4.96$ & $9.420 \pm 6.7$ & \\
\hline
\end{tabular}

myocardial fibrosis and myocardial aneurysms” [21]. Each of these cardiac lesions may lead to mortality or morbidity. Saadoun et al. were reported [12] that one patient died due to endocarditis.

Cardiovascular involvement sometimes manifest as a sudden cardiac death [25]. Previous studies has shown that, sudden cardiac death in patients with BD was more frequent compared with normal population. One of the causes of increased sudden cardiac death in patients with BD is cardiac autonomic dysfunction [26] [27]. Ventricular arrythmias are the most frequent cause of sudden death especially in cardiac disease. Patients with BD have also frequent ventricular arrythmias. Increased QT dispersion and degenerated heart rate variability in BD may be indicators of frequent ventricular arrythmias [9] [23].

Three major factors contribute to the occurence of ventricular arrythmias which lead to the sudden cardiac death. These are arrythmogenic trigerring, arrythmogenic structure and autonomic tonus variability. While arrythmogenic triggering originates from ventricular ectopic activity, arrythmogenic structure derives from the myocardial structure. The third factor is the autonomic tonus variability which is accepted as an impairment of myocardial sympathovagal balance. It is also called cardiac autonomic activity. Since it is difficult to determine cardiac autonomic activity by using only one method, all heart rate variability with baroreflex sensitivity and heart rate turbulence methods should be used to define cardiac autonomic activity [28].

Heart muscle is innervated by autonomic nervous system. Autonomic nervous system consists of afferent and efferent pathways of vagal and sympathetic fibers [29]. Efferent nerves in myocardium may reflect the changes in cardiac autonomic system. Changes in cardiac autonomic system have a crucial role in generation of cardiac arrythmias and sudden death. increased sympathetic and decreased vagal tonus may be the main cause in generation of arrhythmias [28].

Efferent cardiac autonomic activity is mainly under the control of baroreceptor and BRS, and those are related with the mechanism of cardiac arrhythmias. Heart rate turbulence (HRT) values are highly correlated with spontaneous BRS ratios [28]. It is proven that HRT also predicts mortality and sudden cardiac death in various cardiac situations such as postmyocardial infarction [18] after the coronary artery by-pass grafting surgery [30] and chronic heart failure [31]. HRT also predicts the alterations of cardiac autonomic function in non-cardiac diseases such as diabetes mellitus [32] and hyperthyroidism [33]. HRV is also changed in those diseases [34]-[36]. In most studies, cardiac autonomic activity determined by HRT, BRS and HRV were deteriorated but those may not change together even in the same diseases. For example Bigger et al. [37] showed an altered HRV after myocardial infarction but BRS and HRT were normal in the same patient population. Furthermore Ortak et al. [38] showed increased indices of HRV but parameters of HRT did not change in the same patients after myocardial infarction. As a result, HRT and HRV indices may indicate a different aspects of autonomic nervous system activity and they could provide valuable prognostic information value. 
There are limited numbers of studies related with the cardiac autonomic activity in Behcet's disease. Some of the results of these studies are similar but some results are contradictary. cardiac autonomic activity was detected by HRV in all of those studies, whereas our study is the first study, assessing cardiac autonomic activity by using HRT.

As we know from the literature, the results of the most studies assessing cardiac autonomic activity by using HRV are controversial. Ozdemir et al. [39] have shown significantly disturbed parasympathetic activity and normal sympathetic activity in same patients with BD. However Aksoyek et al. [14] concluded that parasympathetic tonus was decreased and sympathetic tonus was increased significantly. Beside this Kirimli et al. [40] did not detect any significant disturbance of cardiac autonomic nervous system in BD patients.

Both Ozdemir et al. and Aksoyek et al. detected significant disturbances of cardiac autonomic activities in BD. However Kirimli et al. did not detect any abnormality of the cardiac autonomic nervous system in BD. Our results were in consistent with the results of Kirimli et al.

We also found that normal cardiac autonomic activity (via HRT) is consistent with Kirimli et al. But our results were different from the other two studies. The First factor is the methodologic differences which may contribute to this contradiction. We evaluated the cardiac autonomic activity via HRT whereas previous three studies evaluated it via HRV. As it is known that HRV and HRT are complementary indicators of cardiac autonomic activity. Either may be normal while the other one is abnormal [37]. Another possible explanation may be the duration of disease. Our patients had a history of average 7 years of BD. The third factor was constitutional and genetic factors which may also play a role in these different results.

The main limitation of our study was the small sample size. The HRT method used in our study could calculate the TO and TS parameters in only half of the patients. Since the HRT parameters should not be calculated in patients without VPB in their Holter recordings. Therefore, the precision of determining HRT will vary depending on the number of VPBs analyzed. The other limitation of our study is the unknown inflammation levels of the patients.

\section{Conclusion}

Consequently, HRT parameters determining the cardiac autonomic dysfunction did not seem to be altered in patients with Behcet's disease. Comprehensive studies related to cardiac autonomic function must be performed in this disease. In addition, these findings need to be confirmed with larger studies.

\section{References}

[1] Caso, F., Costa, L., Rigante, D., Lucherini, O.M., Caso, P., Bascherini, V., Frediani, B., Cimaz, R., Marrani, E., Nieves-Martín, L., Atteno, M., Raffaele, C.G., Tarantino, G., Galeazzi, M., Punzi, L. and Cantarini, L. (2014) Biological Treatments in Behçet’s Disease: Beyond Anti-TNF Therapy. Mediators of Inflammation, 2014, Article ID: 107421. http://dx.doi.org/10.1155/2014/107421

[2] Calamia, K.T., Wilson, F.C., Icen, M., Crowson, C.S., Gabriel, S.E. and Kremers, H.M. (2009) Epidemiology and Clinical Characteristics of Behçet's Disease in the US: A Population-Based Study. Arthritis \& Rheumatology, 15, 600-604. http://dx.doi.org/10.1002/art.24423

[3] Saylan, T., Mat, C., Fresko, I. and Melikoğlu, M. (1999) Behcet’s Disease in the Middle East. Clinics in Dermatology, 17, 209-222. http://dx.doi.org/10.1016/S0738-081X(99)00013-9

[4] Bletry, O., Motattane, A., Wechsler, B., et al. (1998) Cardiac Manifestations of Behçet’s Disease. Twelve Cases. Presse Médicale, 17, 2388-2391.

[5] Huong, D.L., Wechsler, B., Papo, T., de Zuttere, D., Bletry, O., Hernigou, A., Delcourt, A., Godeau, P. and Piette, J.C. (1997) Endomyocardial Fibrosis in Behcet's Disease. Annals of the Rheumatic Diseases, 56, 205-208. http://dx.doi.org/10.1136/ard.56.3.205

[6] Huycke, E.C., Robinowitz, M., Cohen, I.S., Burton, N.A., Fall, S.M., Boling, E. and Hough, D. (1985) Granulomatous Endocarditis with Systemic Embolism in Behcet’s Disease. Annals of Internal Medicine, 102, 791-793. http://dx.doi.org/10.7326/0003-4819-102-6-791

[7] Rolland, J.M., Bical, O., Laradi, A., Robinault, J., Benzidia, R., Vanetti, A. and Herreman, G. (1993) False Aneurysm of the Left Ventricle and Coronary Aneurysms in Behcet Disease. Archives des Maladies du Coeur et des Vaisseaux, 86, 1383-1385. (in French)

[8] Vanhaleweyk, G., el-Ramahi, K.M., Hazmi, M., Sieck, J.O., Zaman, L. and Fawzy, M. (1990) Right Atrial, Right Ventricular and Left Ventricular Thrombi in (İncomplete) Behcet’s Disease. European Heart Journal, 11, 957-959. 
[9] Aytemir, K., Ozer, N., Aksoyek, S., Ozcebe, O., Kabakc1, G. and Oto, A. (1998) Increased QT Dispersion in the Absence of QT Prolongation in Patients with Behçet's Disease and Ventricular Arrhythmias. International Journal of Cardiology, 67, 171-175. http://dx.doi.org/10.1016/S0167-5273(98)00322-2

[10] Borman, P., Tuncay, F., Kocaoğlu, S., Okumuş, M., Güngör, E. and Ekşioğlu, M. (2012) The Subclinic Autonomic Dysfunction in Patients with Behcet Disease: An Electrophysiological Study. Clinical Rheumatology, 31, 41-47. http://dx.doi.org/10.1007/s10067-011-1763-9

[11] Göldeli, O., Ural, D., Komsuoglu, B., Ağaçdiken, A., Dursun, E. and Çetinarslan, B. (1997) Abnormal QT Dispersion in Behçet’s Disease. International Journal of Cardiology, 61, 55-59. http://dx.doi.org/10.1016/S0167-5273(97)00120-4

[12] Saadoun, D., Wechsler, B., Desseaux, K., Le Thi Huong, D., Amoura, Z., Rescher-Rigon, M. and Cacoub, P. (2010) Mortality in Behçet's Disease. Arthritis \& Rheumatism, 62, 2806-2812. http://dx.doi.org/10.1002/art.27568

[13] Schiff, S., Moffatt, R., Mandel, W.J. and Rubin, S.A. (1982) Acute Myocardial Infarction and Recurrent Ventricular Arrhythmias in Behcet's Syndrome. American Heart Journal, 103, 438-440. http://dx.doi.org/10.1016/0002-8703(82)90289-7

[14] Aksoyek, S., Aytemir, K., Ozer, N., Ozcebe, O. and Oto, A. (1999) Assessment of Autonomic Nervous System Function in Patients with Behcet's Disease by Spectral Analysis of Heart Rate Variability. Journal of the Autonomic Nervous System, 77, 190-194. http://dx.doi.org/10.1016/S0165-1838(99)00045-4

[15] Dilsen, G., Oral, A., Aydin, R. and Sabuncu, H. (1991) Autonomic Dysfunction in Behcet’s Disease. In: O’Duffy, J.D. and Kokmen, E., Eds., Behcet's Disease: Basic and Clinical Aspects, Marcel Dekker, New York, 127-132.

[16] Mrowka, R., Persson, P.B., Theres, H. and Patzak, A. (2000) Blunted Arterial Baroreflex Causes "Pathological” Heart Rate Turbulence. American Journal of Physiology. Regulatory, Integrative and Comparative Physiology, 279, R1171R1175.

[17] Roach, D., Koshman, M.L. and Sheldon, R. (2000) Turbulence: A Focal, İnducible, Source of Heart Period Variability Associated with İnduced, Transient Hypertension. Pace, 23, 709.

[18] Schmidt, G., Malik, M., Barthel, P., Schneider, R., Ulm, K., Rolnitzky, L., Camm, A.J., Bigger Jr., J.T. and Schomig, A. (1999) Heart-Rate Turbulence after Ventricular Premature Beats as a Predictor of Mortality after Acute Myocardial İnfarction. Lancet, 353, 1390-1396. http://dx.doi.org/10.1016/S0140-6736(98)08428-1

[19] Suzuki-Krokawa, M. and Suzuki, N. (2004) Behcet’s Disease. Clinical and Experimental Medicine, 4, 10-20. http://dx.doi.org/10.1007/s10238-004-0033-4

[20] Davatchi, F., Shahram, F., Chams-Davatchi, C., Shams, H., Nadji, A., Akhlaghi, M., Faezi, T., Ghodsi, Z., Larimi, R., Ashofteh, F. and Abdollahi, B.S. (2010) Behcet's Disease in Iran: Analysis of 6500 Cases. International Journal of Rheumatic Diseases, 13, 367-373.

[21] Geri, G., Wechsler, B., Thi Huong du, L., Isnard, R., Piette, J.C., Amoura, Z., Resche-Rigon, M., Cacoub, P. and Saadoun, D. (2012) Spectrum of Cardiac Lesions in Behçet Disease: A Series of 52 Patients and Review of the Literature. Medicine (Baltimore), 91, 25-34. http://dx.doi.org/10.1097/MD.0b013e3182428f49

[22] Tursen, U., Gurler, A. and Boyvat, A. (2003) Evaluation of Clinical Findings According to Sex in 2313 Turkish Patients with Behcet’s Disease. International Journal of Dermatology, 42, 346-351. http://dx.doi.org/10.1046/j.1365-4362.2003.01741.X

[23] Kawakami, Y., Nakayama, Y., Nagao, H., Hirota, Y. and Kawamura, K. (1991) A Case of Behçet’s Disease Complicated with Acute Myocardial İnfaction. Kokyu To Junkan, 39, 935-938. (in Japanese)

[24] Kaya, E., Saglam, H., Ciftci, I., Kulac, M., Karaca, S. and Melek, M. (2008) Evaluation of Myocardial Perfusion and Function by Gated SPECT in Patients with Behçet’s Disease. Annals of Nuclear Medicine, 22, 287-295. http://dx.doi.org/10.1007/s12149-007-0115-y

[25] Myerburg, R.J. and Castellanos, A. (2001) Cardiac Arrest and Sudden Cardiac Death. In: Braunwald, E., Ed., Heart Disease: A Textbook of Cardiovascular Medicine, WB Saunders, New York, 890-931.

[26] Akman-Demir, G., Baykan-Kurt, B., Serdaroglu, P., Gurvit, H., Yurdakul, S., Yazici, H., Bahar, S. and Aktin, E. (1996) Seven-Year Follow-Up of Neurologic İnvolvement in Behcet Syndrome. JAMA Neurology, 53, 691-694. http://dx.doi.org/10.1001/archneur.1996.00550070133022

[27] Serdaroglu, P. (1998) Behcet’s Disease and the Nervous System. Journal of Neurology, 245, 197-205. http://dx.doi.org/10.1007/s004150050205

[28] Schwartz, P.J. and Zipes, D.P. (1995) Autonomic Modulation of Cardiac Arrhythmias. In: Zipes, D.P. and Jalife, J., Eds., Cardiac Electrophysiology: From Cell to Bedside, 3rd Edition, Saunders, Philadelphia, 300-314.

[29] Wang, W. and Ma, R. (2000) Cardiac Sympathetic Afferent Reflexes in Heart Failure. Heart Failure Reviews, 5, 57-71. http://dx.doi.org/10.1023/A:1009898107964 
[30] La Rovere, M.T., Bigger Jr., J.T., Marcus, F.I., Mortara, A. and Schwartz, P.J., ATRAMI (Autonomic Tone and Reflexes After Myocardial Infarction) Investigators (1998) Baroreflex Sensitivity and Heart-Rate Variability in Prediction of Total Cardiac Mortality after Myocardial İnfarction. Lancet, 351, 478-484. http://dx.doi.org/10.1016/S0140-6736(97)11144-8

[31] Koyama, J., Watanabe, J., Yamada, A., Koseki, Y., Konno, Y., Toda, S., Shinozaki, T., Miura, M., Fukuchi, M., Ninomiya, M., Kagaya, Y. and Shirato, K. (2002) Evaluation of Heart-Rate Turbulence as a New Prognostic Marker in Patients with Chronic Heart Failure. Circulation Journal, 66, 902-907. http://dx.doi.org/10.1253/circj.66.902

[32] Balcioğlu, S., Arslan, U., Türkoğlu, S., Ozdemir, M. and Cengel, A. (2007) Heart Rate Variability and Heart Rate Turbulence in Patients with Type 2 Diabetes Mellitus with versus without Cardiac Autonomic Neuropathy. American Journal of Cardiology, 100, 890-893. http://dx.doi.org/10.1016/j.amjcard.2007.03.106

[33] Osman, F., Franklyn, J.A., Daykin, J., Chowdhary, S., Holder, R.L., Sheppard, M.C. and Gammage, M.D. (2004) Heart Rate Variability and Turbulence in Hyperthyroidism before, during, and after Treatment. American Journal of Cardiology, 94, 465-469. http://dx.doi.org/10.1016/j.amjcard.2004.04.061

[34] Casolo, G., Balli, E., Taddei, T., Amuhasi, J. and Gori, C. (1989) Decreased Spontaneous Heart Rate Variability in Congestive Heart Failure. American Journal of Cardiology, 64, 1162-1167. http://dx.doi.org/10.1016/0002-9149(89)90871-0

[35] Casolo, G.C., Stroder, P., Signorini, C., Calzolari, F., Zucchini, M., Balli, E., Sulla, A. and Lazzerini, S. (1992) Heart Rate Variability during the Acute Phase of Myocardial İnfarction. Circulation, 85, 2073-2079. http://dx.doi.org/10.1161/01.CIR.85.6.2073

[36] Pagani, M., Malfatto, G., Pierini, S., Casati, R., Masu, A.M., Poli, M., et al. (1988) Spectral Analysis of Heart Rate Variability in the Assessment of Autonomic Diabetic Neuropathy. Journal of the Autonomic Nervous System, 23, 143-153. http://dx.doi.org/10.1016/0165-1838(88)90078-1

[37] Bigger Jr., J.T., La Rovere, M.T., Steinman, R.C., Fleiss, J.L., Rottman, J.N., Rolnitzky, L.M., et al. (1989) Comparison of Baroreflex Sensitivity and Heart Period Variability after Myocardial İnfarction. Journal of the American College of Cardiology, 14, 1511-1518. http://dx.doi.org/10.1016/0735-1097(89)90390-2

[38] Ortak, J., Weitz, G., Wiegand, U.K., Bode, F., Eberhardt, F., Katus, H.A., et al. (2005) Changes in Heart Rate, Heart Rate Variability, and Heart Rate Turbulence during Evolving Reperfused Myocardial İnfarction. Pacing and Clinical Electrophysiology, 28, S227-S232. http://dx.doi.org/10.1111/j.1540-8159.2005.00015.x

[39] Ozdemir, R., Sezgin, A.T., Topal, E., Kutlu, R., Barutcu, I. and Gullu, H. (2003) Findings of Ambulatory Blood Pressure Monitoring and Heart Rate Variability in Patients with Behcet's Disease. American Journal of Cardiology, 92, 646-648. http://dx.doi.org/10.1016/S0002-9149(03)00747-1

[40] Kirimli, O., Aslan, O., Göldeli, O., Güneri, S., Badak, O., Fetil, E. and Ozkan, S. (2000) Heart Rate Variability, Late Potentials and QT Dispersion as Markers of Myocardial Involvement in Patients with Behçet's Disease. Canadian Journal of Cardiology, 16, 345-351.

\section{Abbreviations}

BD: Behcet's disease

HRT: Heart rate turbulence

ISGC: International Study Group Criteria

TO: Turbulence onset

TS: Turbulence slope

HRV: Heart rate variability

BRS: Baroreflex sensitivity

VPB: Ventricular premature beat

SEM: Standard error of mean 
Scientific Research Publishing (SCIRP) is one of the largest Open Access journal publishers. It is currently publishing more than 200 open access, online, peer-reviewed journals covering a wide range of academic disciplines. SCIRP serves the worldwide academic communities and contributes to the progress and application of science with its publication.

Other selected journals from SCIRP are listed as below. Submit your manuscript to us via either submit@scirp.org or Online Submission Portal.
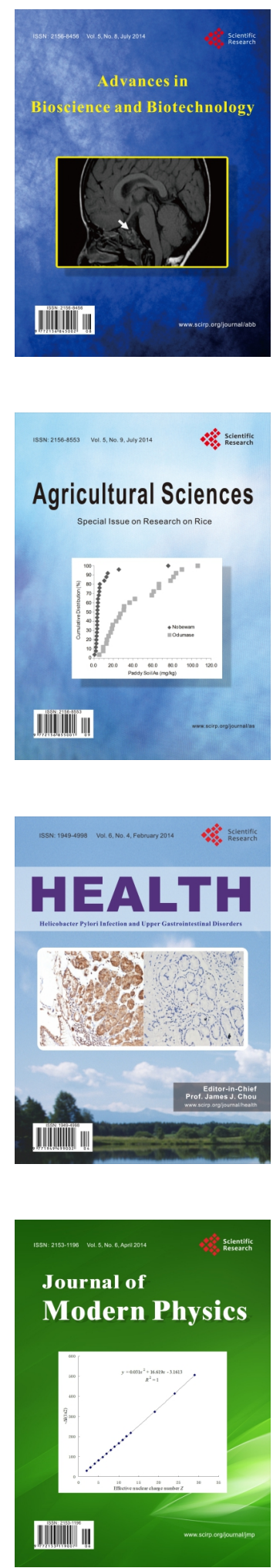
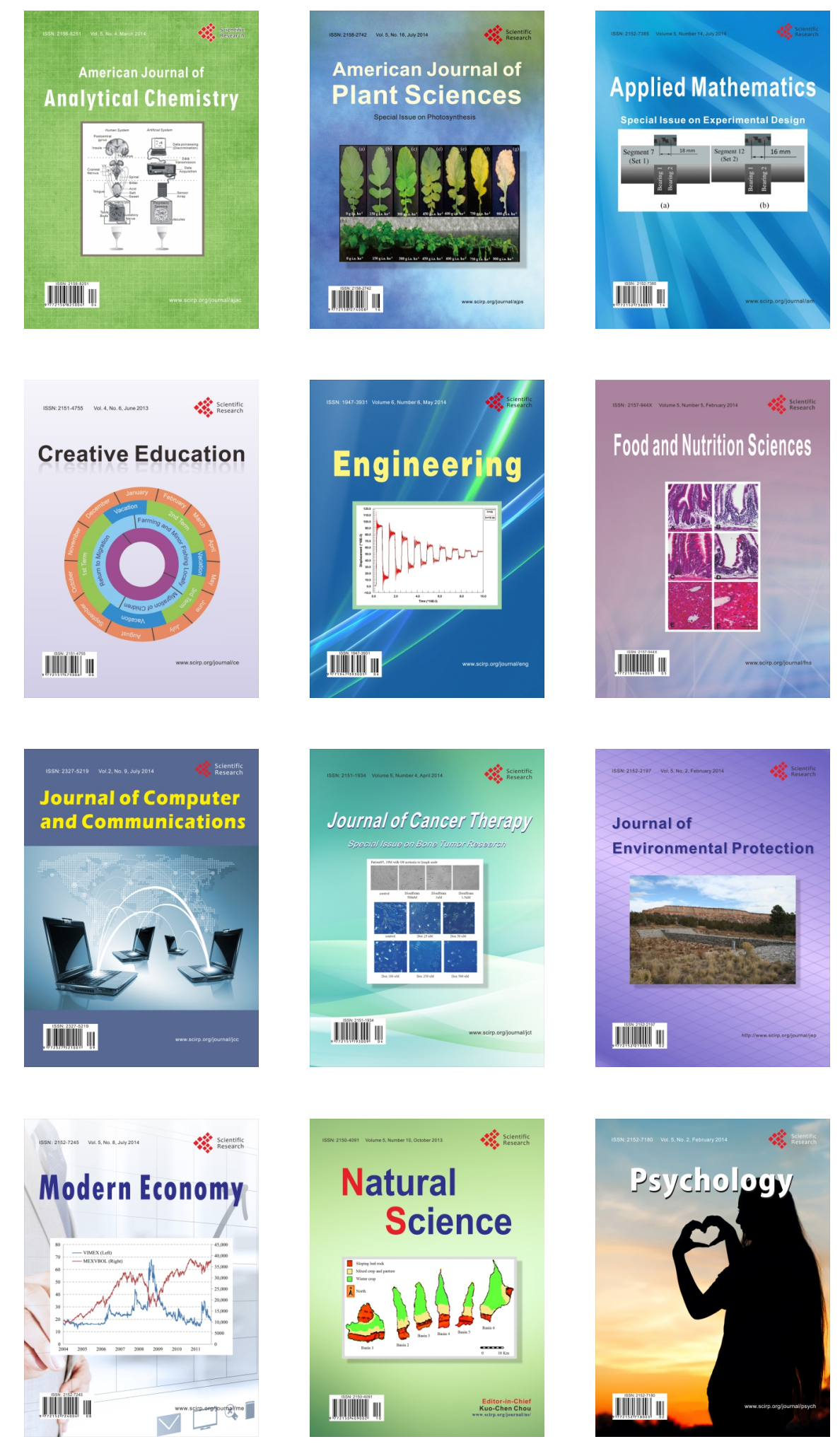